\title{
TITLE:
}

\section{Characteristics of liquid cluster ion beam for surface treatment}

\author{
AUTHOR(S): \\ Ryuto, H.; Ozaki, R.; Kubo, Y.; Takeuchi, M.; \\ Takaoka, G. H.
}

\section{CITATION:}

Ryuto, H. ... [et al]. Characteristics of liquid cluster ion beam for surface treatment. REVIEW OF SCIENTIFIC INSTRUMENTS 2010, 81(2): 02 B902.

\section{ISSUE DATE:}

2010-02

URL:

http://hdl.handle.net/2433/147203

\section{RIGHT:}

Copyright 2010 American Institute of Physics. This article may be downloaded for personal use only. Any other use requires prior permission of the author and the American Institute of Physics. The following article appeared in REVIEW OF SCIENTIFIC INSTRUMENTS81, 02B902 (2010) and may be found at 


\title{
Characteristics of liquid cluster ion beam for surface treatment ${ }^{a)}$
}

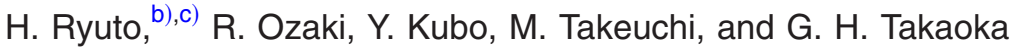 \\ Photonics and Electronics Science and Engineering Center, Kyoto University, Kyoto 615-8510, Japan
}

(Presented 24 September 2009; received 11 September 2009; accepted 3 October 2009; published online 4 February 2010)

\begin{abstract}
A liquid cluster ion source, which is an ion source for the cluster beams produced with liquid materials, has been developed for the surface treatment of solid materials. The electrodes were designed for increasing the cluster beam intensity by a computer simulation of beam trajectories. The peaks of the cluster size distributions of the water and ethanol cluster ion beams of $3 \mathrm{~atm}$ vapor pressure were approximately at $2.4 \times 10^{3}$ and $1.6 \times 10^{3}$ molecules, respectively. The cluster size distributions of ethanol clusters were not sensitive to the variations of the acceleration voltages $\left(V_{\mathrm{e}}\right)$ and currents $\left(I_{\mathrm{e}}\right)$ of the electrons for ionization when the $V_{\mathrm{e}}$ and $I_{\mathrm{e}}$ were larger than approximately $200 \mathrm{~V}$ and $200 \mathrm{~mA}$, respectively. (C) 2010 American Institute of Physics. [doi:10.1063/1.3264627]
\end{abstract}

\section{INTRODUCTION}

The cluster ion beam technique is one of the newly developed ion beam technique that is attracting much interest in various fields such as the semiconductor industry and medical application. A cluster beam is a flow of aggregates of atoms or molecules combined typically with van der Waals force. The condensation phenomenon in an expanding nozzle flow was originally investigated by the Karlsruhe group $^{1,2}$ and unique properties of cluster ion beams were revealed during the decades of investigation by various groups. In addition, the production of clusters from vaporized materials without helium gas was investigated. ${ }^{3-5}$ As well as the properties of the cluster itself, the impact of a cluster ion on a solid surface represents unique properties, which do not appear in the conventional ion beam process. A high sputtering yields, low radiation damage, and surface smoothing effect are the typical features of the interaction between cluster ion beams and solid materials. ${ }^{6}$ These features are expected to be the key to applying the cluster ion beam technique in the semiconductor industry, which requires a rapid processing without serious radiation damage. The possibility to use the cluster ion beam technique in medical applications was also investigated. ${ }^{7}$ These characteristic properties of the interaction between cluster ion beams and solid surfaces are mainly attributable to the high-density energy deposition and the low-energy irradiation effect.

Moreover, a liquid cluster ion beam, that is a cluster ion beam produced with a liquid material (at room temperature), has unique properties that are induced by the characteristic structure as well as the chemical properties of the molecules that comprise the cluster. Therefore, a liquid cluster ion beam is expected to be a powerful tool to process or modify solid surfaces. Therefore, we have developed a liquid cluster ion source to realize a high intensity cluster ion beam that can be used in the applications in various fields.

\footnotetext{
a) Contributed paper, published as part of the Proceedings of the 13th International Conference on Ion Sources, Gatlinburg, Tennessee, September 2009.

${ }^{b)}$ Electronic mail: ryuto@kuee.kyoto-u.ac.jp.

${ }^{c}$ Formerly, H. Akiyoshi.
}

\section{EXPERIMENTAL APPARATUS}

Figure 1 shows a schematic view of the liquid cluster ion source and the focusing elements. The liquid clusters were produced by the adiabatic expansion method. A liquid material such as ethanol and water is filled in the liquid container. In the case of an ethanol cluster ion beam, $150 \mathrm{ml}$ of ethanol is filled in the liquid container for approximately $2 \mathrm{~h}$ irradiation. The liquid material is heated to increase vapor pressure using a heater attached on the outer wall of the liquid container. For example, the ethanol temperature is increased to $382 \mathrm{~K}$ and the water temperature is increased to $407 \mathrm{~K}$ to obtain $0.3 \mathrm{MPa}$ vapor pressure. The typical variation of the temperature is approximately $\pm 1 \mathrm{~K}$, which corresponds to \pm 10 and $\pm 9 \mathrm{kPa}$ variations of ethanol and water vapor pressures, respectively. The vaporized liquid material is ejected to a vacuum chamber through a Laval nozzle. The temperature of the vapor decreases by the adiabatic expansion, and clusters are formed. ${ }^{8}$ The core portion of the flow of neutral clusters is selected using a skimmer to avoid the disintegration of clusters caused by shockwaves. The skimmer opening is $1.3 \mathrm{~mm}$. The remaining vapor is evacuated using a roots pump. The other vacuum chambers downstream are evacuated using diffusion pumps or a turbo molecular pump to avoid the disintegration of clusters by collisions with residual gases.

The neutral clusters are ionized by the electrons emitted from the loop of a tungsten filament. The typical acceleration voltage of the electrons $\left(V_{\mathrm{e}}\right)$ and their currents $\left(I_{\mathrm{e}}\right)$ are $200 \mathrm{~V}$ and $200 \mathrm{~mA}$, respectively. Singly charged cluster ions are assumed in the following discussion. The ionized clusters are extracted by the voltage applied between the anode and the extraction electrode. Then, the monomers and small-sized clusters are eliminated by the retarding voltage method. The retarding voltage method is based on the phenomenon that the velocity of the nozzle flow is highly uniform, typically within $10 \%{ }^{2,9}$ The kinetic energy of ethanol clusters calculated on the basis of this phenomenon is $0.29 \mathrm{eV} /$ molecule. Therefore, the ethanol cluster whose cluster size (number of molecules that comprise a cluster) is less than 100 is blocked by the retarding voltage $\left(V_{\mathrm{r}}\right)$ of $29 \mathrm{~V}$ applied to the retarding 


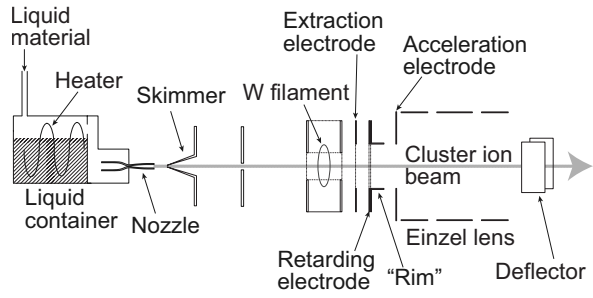

FIG. 1. Schematic diagram of liquid cluster ion source and electrostatic lens.

electrode. The position and shape of the electrodes were designed for increasing the intensity of the cluster ion beam by trajectory simulations. The openings of the extraction and retarding electrodes are covered by high-transmission nickel fine meshes to make flat equipotential surface. The cluster ion beam is accelerated by an acceleration voltage $\left(V_{\mathrm{a}}\right)$ typically from 3 to $9 \mathrm{kV}$. The accelerated cluster ion beam is transported to the target using an Einzel lens and electrostatic deflector. The Einzel lens voltage $\left(V_{1}\right)$ was typically from 0 to $15 \mathrm{kV}$. The target and a Faraday cup with an electron suppressor approximately at $-300 \mathrm{~V}$ are set on a linear motion feedthrough.

The cluster size distribution was measured by the timeof-flight (TOF) method. A pulse of an ethanol cluster ion beam was produced by the electrostatic deflector, on which a high voltage pulse was applied. In this work, the beam signal was measured using a Faraday cup instead of a microchannel plate to measure the cluster size distribution of intense cluster ion beams suitable for the application in the semiconductor industry or medical application. The signal extracted from the Faraday cup was observed using a digital oscilloscope. The calculation was made nonrelativistically because the $\beta$ was approximately in the order of $10^{-5}$. The mass

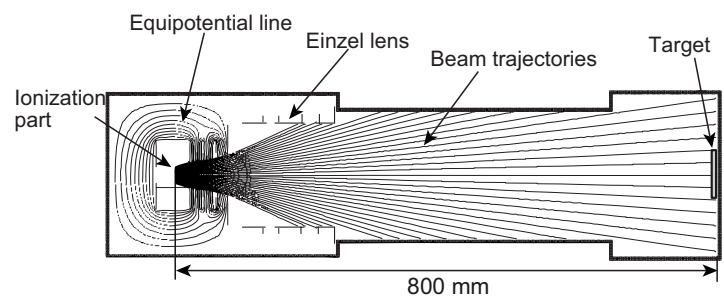

(a)

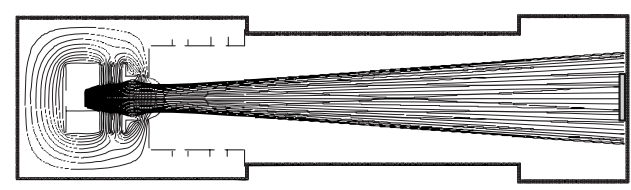

(b)

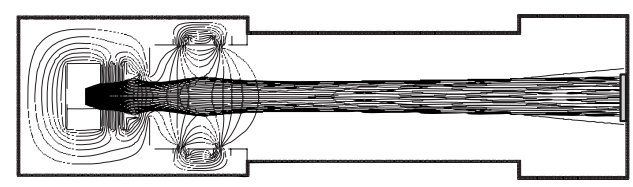

(c)

FIG. 2. Equipotential line and trajectories of ethanol cluster ion beams whose cluster size is 1000 with (a) retarding electrode without rim and $V_{1}$ $=0 \mathrm{~V}$, (b) retarding electrode with $15 \mathrm{~mm}$ long rim and $V_{1}=0 \mathrm{~V}$, and (c) retarding electrode with $15 \mathrm{~mm}$ long rim and $V_{1}=8 \mathrm{kV}$.

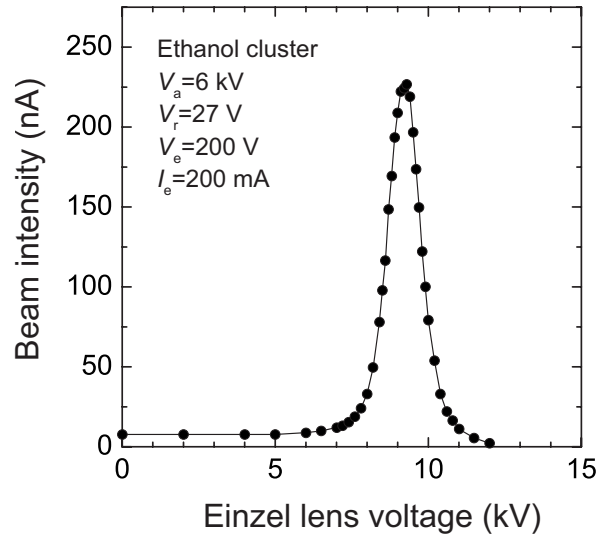

FIG. 3. Dependence of beam intensity on Einzel lens voltage measured using Faraday cup with $10 \mathrm{~mm}$ diameter collimator.

resolution of a linear TOF system is limited, but sufficient to know the shape of the cluster size distribution in general.

\section{RESULTS AND DISCUSSION}

Figure 2 shows equipotential lines and trajectories of ethanol cluster ion beams whose cluster size is 1000 with (a) a flat retarding electrode without focusing using the Einzel

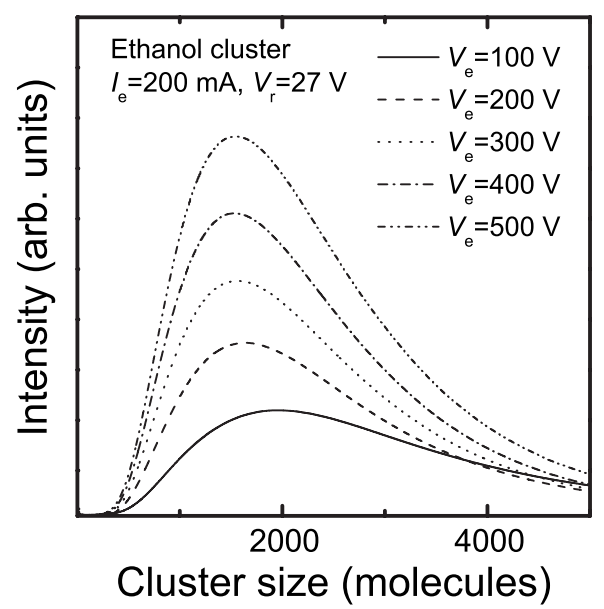

(a)

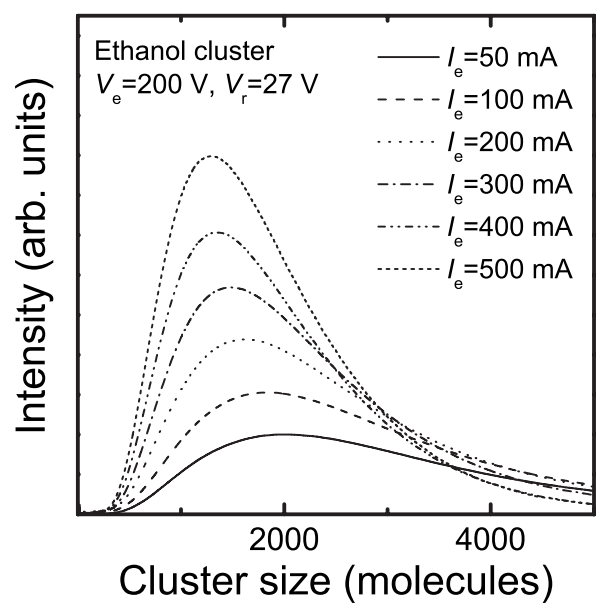

(b)

FIG. 4. Dependences of cluster size distribution on (a) acceleration voltage and (b) current of electrons for ionization. 
TABLE I. Statistical values of cluster size distributions.

(a) $V_{\mathrm{e}}$ dependence with $I_{\mathrm{e}}=200 \mathrm{~mA}$

\begin{tabular}{|c|c|c|c|c|c|c|c|}
\hline$V_{\mathrm{e}}(\mathrm{V})$ & 100 & 200 & 300 & 400 & & 500 & \\
\hline Mode $\left(\times 10^{3}\right)$ & 2.0 & 1.6 & 1.5 & 1.5 & & 1.5 & \\
\hline Median $\left(\times 10^{3}\right)$ & 2.8 & 2.2 & 2.1 & 2.1 & & 2.1 & \\
\hline FWHM $\left(\times 10^{3}\right)$ & 2.9 & 2.3 & 2.2 & 2.2 & & 2.2 & \\
\hline \multicolumn{8}{|c|}{ (b) $I_{\mathrm{e}}$ dependence with $V_{\mathrm{e}}=200 \mathrm{~V}$} \\
\hline$I_{\mathrm{e}}(\mathrm{mA})$ & 50 & 100 & 200 & 300 & 400 & & 500 \\
\hline Mode $\left(\times 10^{3}\right)$ & 2.0 & 1.8 & 1.6 & 1.5 & 1.3 & & 1.3 \\
\hline Median $\left(\times 10^{3}\right)$ & 2.8 & 2.5 & 2.3 & 2.0 & 1.7 & & 1.7 \\
\hline FWHM $\left(\times 10^{3}\right)$ & 3.0 & 3.0 & 2.3 & 2.1 & 1.8 & & 1.7 \\
\hline
\end{tabular}

lens, (b) a retarding electrode with 15-mm-long "rim" (see Fig. 1) without focusing using the Einzel lens, and (c) a retarding electrode with $15 \mathrm{~mm}$ long rim and the Einzel lens voltage of $8 \mathrm{kV}$. The calculation was performed using the ion and electron optics simulator SIMION. In the case of the flat electrode for retarding voltage [Fig. 2(a)], the ethanol cluster ion beam hit the inner surface of the Einzel lens. A high transport efficiency of the ethanol cluster ion beam is hardly expected in this case. When a retarding electrode with 15-mm-long rim was used in the simulation, the focusing of the ethanol cluster ion beam was drastically improved. The ethanol cluster ion beam fully cleared the electrodes of the Einzel lens [Fig. 2(b)]. The focusing of the ethanol cluster ion beam was further improved when an Einzel lens voltage of $8 \mathrm{kV}$ was applied and an almost parallel beam was realized at the target position [Fig. 2(c)]. Therefore, a retarding electrode with a $15-\mathrm{mm}$ rim was used in the liquid cluster ion beam apparatus.

Figure 3 shows a dependence of the beam intensity of an ethanol cluster ion beam on the Einzel lens voltage. The beam intensity was measured using a Faraday cup with a 10 $\mathrm{mm}$ diameter collimator. The maximum beam intensity of the ethanol cluster ion beam was obtained at the Einzel lens voltage of $9.3 \mathrm{kV}$. The ethanol cluster ion beam may be overfocused by the $9.3 \mathrm{kV}$ Einzel lens voltage to pass the 10 $\mathrm{mm}$ diameter collimator efficiently. The maximum beam current density was approximately $290 \mathrm{nA} / \mathrm{cm}^{2}$.

Figure 4 shows dependences of the cluster size distribution of ethanol cluster ion beams on the (a) $V_{\mathrm{e}}$ and (b) $I_{\mathrm{e}}$. The vertical sizes were scaled for easy comparison. Table I shows the statistical values of the cluster size distributions in Fig. 4. The peak position of the cluster size distribution of ethanol clusters shifted to the smaller side with increase in the $V_{\mathrm{e}}$. However, the shifts of the mode, median, and full width at half maximum (FWHM) were small when the $V_{\mathrm{e}}$ was larger than $200 \mathrm{~V}$ and became constants when the $V_{\mathrm{e}}$ was larger than $300 \mathrm{~V}$. It was reported that the ratio of multiply charged cluster ions increases with increase in the $V_{\mathrm{e}}$, and has a broad maximum approximately from 100 to $500 \mathrm{~V}{ }^{10}$ The range of the $V_{\mathrm{e}}$ in the present measurement coincided with this broad maximum. On the other hand, the peak position of the cluster size distribution of ethanol clusters also shifted to the smaller side with increase in the $I_{\mathrm{e}}$. This tendency may be explained by the larger ionization cross section of larger-sized clusters than smaller-sized clusters. As the case in the $V_{\mathrm{e}}$, the shift of the peak position caused by the increase in the $I_{\mathrm{e}}$ was limited when the $I_{\mathrm{e}}$ was larger than $200 \mathrm{~mA}$. The variations of the mode, median, and FWHM gradually decreased with increasing $I_{\mathrm{e}}$ and became almost constant when the $I_{\mathrm{e}}$ was larger than $400 \mathrm{~mA}$. Therefore, the cluster size distribution of an ethanol cluster ion beam can be well controlled by adjusting the acceleration voltage and current of the electrons for ionization with moderate accuracy when the $V_{\mathrm{e}}$ and $I_{\mathrm{e}}$ are larger than approximately $200 \mathrm{~V}$ and $200 \mathrm{~mA}$, respectively. This phenomenon is useful to realize a reproducible precise processing of high-density semiconductor devises, because the sputtering yield, radiation damage, and surface smoothing effects depend on the cluster size distribution. ${ }^{6}$

\section{SUMMARY}

A liquid cluster ion source was developed for surface treatment. To increase the cluster beam intensity, the electrodes are designed by the optics simulation. The maximum beam current density of the ethanol cluster ion beam realized by the apparatus was $290 \mathrm{nA} / \mathrm{cm}^{2}$. The cluster size distribution of ethanol clusters was not sensitive to the variations of the acceleration voltage and current of the electrons for ionization when the $V_{\mathrm{e}}$ and $I_{\mathrm{e}}$ were larger than $200 \mathrm{~V}$ and $200 \mathrm{~mA}$, respectively. Therefore, the liquid cluster ion beam can be a powerful tool to realize a reproducible processing of solid surfaces.

${ }^{1}$ E. W. Becker, K. Bier, and W. Henkes, Z. Phys. 146, 333 (1956).

${ }^{2}$ O. F. Hagena and W. Obert, J. Chem. Phys. 56, 1793 (1972).

${ }^{3}$ T. Takagi, I. Yamada, M. Kunori, and S. Kobiyama, Proceedings of the Second International Conference on Ion Sources, Vienna, 1972 (unpublished), p. 2121.

${ }^{4}$ I. Yamada and G. H. Takaoka, Jpn. J. Appl. Phys., Part 1 32, 2121 (1993).

${ }^{5}$ G. H. Takaoka, H. Noguchi, K. Nakayama, and M. Kawashita, Rev. Sci. Instrum. 77, 03B509 (2006)

${ }^{6}$ H. Ryuto, K. Sugiyama, R. Ozaki, and G. H. Takaoka, Appl. Phys. Express 2, 016504 (2009).

${ }^{7}$ M. Kawashita, H. Shimatani, S. Itoh, R. Araki, and G. H. Takaoka, J. Ceram. Soc. Jpn. 114, 77 (2006).

${ }^{8}$ O. F. Hagena, in Molecular Beams and Low Density Gas Dynamics, edited by P. P. Wegener (Dekker, New York, 1974), pp. 93-181.

${ }^{9}$ O. F. Hagena and K. Varma, Rev. Sci. Instrum. 39, 47 (1968).

${ }^{10}$ W. Obert, Int. J. Mass Spectrom. Ion Phys. 9, 295 (1972). 